\title{
Correction: Going Beyond Panaceas: The Diversity of Land Observatory Forms in Africa. Land 2020, 9, 70
}

\author{
Quentin Grislain 1,2,3,4,* Jeremy Bourgoin 1,2@ , Ward Anseeuw 2,5,6, Perrine Burnod 1,7, \\ Eva Hershaw ${ }^{6}$ and Djibril Diop ${ }^{8}$ \\ 1 UMR TETIS, CIRAD, F-34398 Montpellier, France; jeremy.bourgoin@cirad.fr (J.B.); \\ perrine.burnod@cirad.fr (P.B.) \\ 2 Land Matrix Initiative, 00010 Rome, Italy; w.anseeuw@landcoalition.org \\ UMR 8586-PRODIG, F-93322 Aubervilliers, France \\ Université Paris 1 Panthéon-Sorbonne, F-75231 Paris, France \\ UMR ART-DEV, CIRAD, F-34398 Montpellier, France \\ International Land Coalition, 00010 Rome, Italy; e.hershaw@landcoalition.org \\ Madagascar Land Observatory, 101 Antananarivo, Madagascar \\ 8 Institut Sénégalais de Recherches Agricoles, Bureau d'Analyses Macro-Economiques, \\ BP 3120 Dakar, Senegal; djibrildiopsn@gmail.com \\ * Correspondence: quentin.grislain@cirad.fr
}

Received: 6 May 2020; Accepted: 18 June 2020; Published: 6 July 2020

The authors wish to make the following corrections to this paper [1]:

Major revisions:

1. Following the publication of the article, several partners pointed out important inaccuracies in the Discussion and Conclusion sections that were overlooked in the final manuscript. These points poorly reflect on actual land-related dynamics and hence, the following sentences and sections should be removed:

(a) Section 4.1. We would like to remove paragraph 2 (but not the first sentence) and the first two sentences in paragraph 3: "We are not in favor of the general standardization of intrinsically heterogeneous institutions. This process of homogenization has long been criticized, especially due to resultant failure in assessing impacts in a normative way [11]. It must be acknowledged that not all land observatories share the same objectives or have the same impacts. Differences are presented in terms of outcomes, and, looking beyond the general enthusiasm for land observatories, we show that these institutions are not necessarily designed to improve land governance or to participate in public action." The process of standardization was a general comment. We do not have enough evidence to confirm that this process of standardization effectively concerned land observatories. The role of land observatories in relation to land governance and public action will require further research. This paper does not expose enough results on the matter for this point to be developed here.

(b) Section 4.3. We would like to remove the whole section entitled, "The over-representation of International donors in the emergence of national land observatories: Pushing a certain vision of land governance." This section put an emphasis on donors and especially highlighted one particular donor. The idea, not clearly exposed here, was to insist on the importance of studying all actors involved in land governance (civil society, academics, private actors, different ministries, etc.) and, for each type of actor, to analyze the different practices (and not to focus on one specific organization). The section here is not clear and draws on facts and references that need to be crosschecked. 
2. Section 5. We would like to replace the last sentence in the Conclusion with: "The concrete impacts of land observatories in land governance, power relations between actors (within and outside the observatories), and the strategies implemented by observatories to access and share land-related information, will have to be further analyzed." Indeed, this article does not deal with these points, which will be the subject of another article.

3. Section 3.2, last paragraph. We would like to remove the last three sentences, namely: "The ubiquity of international donors in the financing of land observatories raises the question of the independence of these structures in the conduct of their activities. More generally, it also refers to the sovereignty of States over the conduct and implementation of public land policies. This issue will be addressed in the discussion section." The role of donors is to be further analyzed and is announced in the Conclusion. The issue of sovereignty is not appropriate here.

4. Section 3.3, last paragraph. We would like to remove the last sentence, namely: "By identifying new cases of large-scale acquisitions, the land observatory in Uganda has established itself as a prominent institution for land governance and a central decision-making tool for the management and regulation of large-scale land acquisitions." This argument does not reflect that fact on the ground.

\section{Minor revisions:}

1. We would like to modify the affiliations as there was a confusion between the addresses of the research unit (UMR PRODIG) and the Université Paris 1 Panthéon-Sorbonne. We would like to change the following affiliation "3UMR Prodig, Université Paris 1 Panthéon-Sorbonne, F-93322 Paris, France" to "3 UMR 8586 - PRODIG, F-93322 Aubervilliers, France" and "4 Université Paris 1 Panthéon-Sorbonne, F-75231 Paris, France".

(a) "3UMR Prodig, Université Paris 1 Panthéon-Sorbonne, F-93322 Paris, France" has to be changed to "3UMR 8586 - PRODIG, F-93322 Aubervilliers, France"

(b) "UMR ART-DEV, CIRAD, F-34398 Montpellier, France" has to be changed to "4 Université Paris 1 Panthéon-Sorbonne, F-75231 Paris, France"

(c) "International Land Coalition, 00010 Rome, Italy" has to be changed to " ${ }^{5} \mathrm{UMR}$ ART-DEV, CIRAD, F-34398 Montpellier, France"

(d) "6Madagascar Land Observatory, 101 Antananarivo, Madagascar" has to be changed to "6 International Land Coalition, 00010 Rome, Italy"

(e) “7 Institut Sénégalais de Recherches Agricoles, Bureau d'Analyses Macro-Economiques, BP 3120 Dakar, Senegal" has to be changed to "7 Madagascar Land Observatory, 101 Antananarivo, Madagascar"

(f) We would like to add "8 Institut Sénégalais de Recherches Agricoles, Bureau d'Analyses Macro-Economiques, BP 3120 Dakar, Senegal"

Thus, the affiliations numbers are as follows:

(a) "Quentin Grislain 1, 2, 3" has to be changed to "Quentin Grislain 1, 2, 3, 4"

(b) "Ward Anseeuw 2, 4, 5" has to be changed to "Ward Anseeuw 2, 5, 6"

(c) "Perrine Burnod 1, 6" has to be changed to "Perrine Burnod 1, 7"

(d) "Eva Hershaw 5" has to be changed to "Eva Hershaw 6"

(e) "Djibril Diop 7" has to be changed to "Djibril Diop 8"

The updated affiliations are as follow:

Quentin Grislain 1,2,3,4,*, Jeremy Bourgoin 1,2, Ward Anseeuw 2,5,6, Perrine Burnod 1,7, Eva Hershaw 6 and Djibril Diop 8 
1. UMR TETIS, CIRAD, F-34398 Montpellier, France; jeremy.bourgoin@cirad.fr (J.B.); perrine.burnod@cirad.fr (P.B.)

2. Land Matrix Initiative, 00010 Rome, Italy; w.anseeuw@landcoalition.org

3. UMR 8586 - PRODIG, F-93322 Aubervilliers, France

4. Université Paris 1 Panthéon-Sorbonne, F-75231 Paris, France

5. UMR ART-DEV, CIRAD, F-34398 Montpellier, France;

6. International Land Coalition, 00010 Rome, Italy; e.hershaw@landcoalition.org

7. Madagascar Land Observatory, 101 Antananarivo, Madagascar

8. Institut Sénégalais de Recherches Agricoles, Bureau d'Analyses Macro-Economiques, BP 3120 Dakar, Senegal; djibrildiopsn@gmail.com

2. Introduction. We would like to add the abbreviation: "the Senegal National Land Governance Observatory (ONGF)".

3. Section 2.1. We would like to add the abbreviation (UEMOA) after (Member States of The West African Monetary and Economic Union)."

4. Section 2.1, last paragraph. We would like to remove "(only)". The adjective unnecessarily burdens the sentence.

5. Section 2.2. We would like to add Cirad's full name behind it, as: Centre de coopération internationale en recherche agronomique pour le développement (Cirad).

6. We would like to change the following phrase, "land reforms", to reflect "land reform". Because we are referring to the 2005 land reform in Madagascar, we must use the singular and not the plural. These changes appear in the following passages:

(a) Table 1,

(b) Section 3.2, first paragraph.

(c) Section 3.3, first paragraph.

(d) Section 3.5, there are three "land reforms" to change into "land reform" in the fourth paragraph.

(e) Section 4.1, there are three "land reforms" to change into "land reform", one in the fourth paragraph and two in the las paragraph.

7. Section 3.2, second paragraph. We would like to change: "In Senegal, the land observatory (ONGF)" to "In Senegal, the National Land Governance Observatory (ONGF)".

8. Section 3.3, first sentence. We would like to remove the first sentence, namely: "There are multiple land related observation domains: agriculture, forestry, fishing and other maritime domains, animal husbandry, etc." This sentence is useless and does not provide additional information.

9. Section 3.3, first paragraph. We would like to modify the sentence: "In contrast, the Burkina Faso land observatory ... action plan" to "In contrast, the National Land Observatory in Burkina Faso (ONF-BF) has come in for criticism for the over-ambitious scope of its five-year observation action plan".

10. Section 3.4, the second paragraph. We would like to remove: " action is never taken by a multi stakeholder group or civil society". This is a repetition of the previous sentence.

11. Section 4.2, first sentence in the second paragraph. We would like to change "laboratory's" to "land observatory's". This is a typo we have overlooked.

We apologize for any inconvenience. The manuscript will be updated, and the original version will remain available online.

Acknowledgments: We thank André Teyssier and Rivo Andrianirina Ratsialonana for bringing to our attention several issues following the publication of the article.

Conflicts of Interest: The authors declare no conflict of interest. 


\section{Reference}

1. Grislain, Q.; Bourgoin, J.; Anseeuw, W.; Burnod, P.; Hershaw, E.; Diop, D. Going Beyond Panaceas: The Diversity of Land Observatory Forms in Africa. Land 2020, 9, 70. [CrossRef] 